\title{
Incidence and Predicted Risk Factors of Pressure Ulcers in Surgical Patients: Experience at a Medical Center in Taipei, Taiwan
}

\author{
Ling Fu Shaw, ${ }^{1,2}$ Pao-Chu Chang, ${ }^{1}$ Jung-Fen Lee, ${ }^{1}$ Huei-Yu Kung, ${ }^{1}$ and Tao-Hsin Tung,4 \\ ${ }^{1}$ Department of Nursing, Taipei Veterans General Hospital, Taipei 11220, Taiwan \\ ${ }^{2}$ Faculty of Nursing, School of Nursing, Yang-Ming University, Taipei 11220, Taiwan \\ ${ }^{3}$ Department of Medical Research and Education, Cheng Hsin General Hospital, Taipei 11220, Taiwan \\ ${ }^{4}$ Faculty of Public Health, School of Medicine, Fu Jen Catholic University, Taipei 24205, Taiwan
}

Correspondence should be addressed to Tao-Hsin Tung; ch2876@gmail.com

Received 19 March 2014; Revised 3 June 2014; Accepted 3 June 2014; Published 26 June 2014

Academic Editor: Giuseppe Valacchi

Copyright (c) 2014 Ling Fu Shaw et al. This is an open access article distributed under the Creative Commons Attribution License, which permits unrestricted use, distribution, and reproduction in any medium, provided the original work is properly cited.

\begin{abstract}
Purpose. To explore the context of incidence of and associated risk factors for pressure ulcers amongst the population of surgical patients. Methods. The initial study cohort was conducted with a total of 297 patients admitted to a teaching hospital for a surgical operation from November 14th to 27th 2006 in Taipei, Taiwan. The Braden scale, pressure ulcers record sheet, and perioperative patient outcomes free from signs and symptoms of injury related to positioning and related nursing interventions and activities were collected. Results. The incidence of immediate and thirty-minute-later pressure ulcers is 9.8\% (29/297) and 5.1\% (15/297), respectively. Using logistic regression model, the statistically significantly associated risk factors related to immediate and thirtyminute-later pressure ulcers include operation age, type of anesthesia, type of operation position, type of surgery, admission Braden score, and number of nursing intervention after adjustment for confounding factors. Conclusion. Admission Braden score and number of nursing intervention are well-established protected factors for the development of pressure ulcers. Our study shows that older operation age, type of anesthesia, type of operation position, and type of surgery are also associated with the development of pressure ulcers.
\end{abstract}

\section{Introduction}

Pressure ulcers are known as bed scores and decubitus ulcers and occur mainly in parts of the body that are subject to high pressure from body weight on bony prominences [1]; thus they have been defined as "an area of unrelieved pressure usually over a bony prominence leading to ischemia, cell death, and tissue necrosis" [2]. This disease often manifests negative outcomes for patients after surgeries, which may include pain, additional treatment and surgery, longer hospital stays, disfigurement or scarring, increased morbidity, and increased medical costs [3]. The development of pressure ulcer in hospitalized patients who have undergone a surgical procedure is also prompted [2-6]. In addition, pressure ulcers have been described as one of the most costly and physically debilitating complications in the 20th century [7]. Because pressure ulcers remain a major health postsurgery problem; identification of patients at risk for pressure ulcer development is imperative for implementing cost-effective, evidence-based preventive measures. Continuous risk assessment could be viewed as the continuous clinical view and judgment of the patient's pressure ulcers risk, with the goal of conducing preventive measures that meet the particular risk factor.

A multidisciplinary method is necessary in pressure prevention and treatment and a large part of the responsibility falls on nurses in this approach [5]. From the viewpoint of preventive medicine, it is important to not only be cognizant of the background morbidity of pressure ulcers regionally, but also explore the complete spectrum of demographic and biological markers which may be related to the development 
of pressure ulcers. Although numerous studies focusing on morbidity and risk factors of pressure ulcers have been conducted in western countries [6-9], to the best of our knowledge, however, such studies are limited-few national or local databases of surgical patients' records regarding pressure ulcers morbidity are found in Taiwan. It is essential to identify patients at risk and to plan appropriate interventions to prevent the development of pressure ulcers [5]. In order to improve the quality of care for patients with surgical operation, it is necessary for the healthcare professionals in Taiwan to acquire knowledge of the risks for pressure ulcers development and clinical risk factors and further preventive measurement pertaining to pressure ulcers is also necessary. Nurses are also responsible in the places they work for identifying patients at risk for pressure ulcers and for carrying out the pressure ulcer preventive measures [5]. This study is designed to explore the potential perioperative factors and related nursing interventions and activities then to improve the understanding of the overall pathogenesis of pressure ulcers. The purpose of this study is to explore the context of immediate and thirty-minute-later incidence of and associated risk factors for pressure ulcers amongst the population of surgical patient, as determined by the application of the subjects' study program at a fully certified medical center and teaching hospital in Taipei, Taiwan.

\section{Methods}

2.1. Study Design and Sample Selection. This study was conducted in a medical center in Northern Taiwan. The research sample included patients who agreed to participate, who were 18 years old or older, who were able to communicate in either Mandarin or Taiwanese, having had a first time elective surgery and a surgical procedure lasting more than 30 minutes under spinal or general anaesthesia, and who had neither existing pressure ulcers nor any traumas before surgery. The study spanned from November 14 th to 27 th, 2006. Patients were enrolled from the medical specialisms of cardiovascular, general surgery, chest surgery, orthopedic surgery, neurosurgery, plastic surgery, and urologic surgery. The investigation was of an observational follow-up study design, and therefore the study sample selected all patients who were listed on the surgical elective schedule during the research period. Finally, a total of 297 patients agreed to participate in the study. Table 4 shows the study flowchart of the recruitment. Written permission was obtained from the study institution and managements that were involved. Informed consents in this study were obtained verbally from the patients prior to surgery. The surgeons and perioperative nurses of the operating room were also informed about the procedure of the study. All procedures were performed in accordance with the guidelines of ethics and adhered to the tenets of the Declaration of Helsinki. All subjects' information remained anonymous and was only used for analytical purposes.

2.2. Data Collection. Data were collected by using structured questionnaires including The Braden Pressure Ulcer Risk
Assessment scale (a summated rating scale made up of six subscales scored from 1 to 3 or 4 , for total scores that range from 6 to 23; a lower Braden scale score indicates a lower level of functioning and, therefore, a higher level of risk for pressure ulcer development) [10], pressure ulcers record sheet, perioperative patient outcomes free from signs and symptoms of injury related to positioning and related nursing interventions and activities, operation time, type of anesthesia and surgical positioning, body temperature and blood pressure, occurrence of shear power and wetness during operation, and use of heart-lung machine. Demographic characteristics such as gender, age, body mass index, personal past diseases, and nutrition were assessed preoperatively by perioperative nurse leaders. The type of anesthesia and surgical positioning, use of heart-lung machine, measurement of blood pressure during operation, and the occurrence of shear power and wetness were collected intraoperatively. Body temperature was observed immediately after surgical operation.

Pressure ulcers were defined by the National Pressure Ulcer Advisory Panel (NPUAP) and European Pressure Ulcer Advisory Panel (EPUAP) as "localized injury to the skin and/or underlying tissue usually over a bony prominence as a result of pressure or pressure in combination with shear and/or friction" $[2,11]$. In this study, the perioperative nurse leaders and nurses of the operating room and postanesthesia recovery room who participated in the study were informed about the study design and received a pressure ulcer assessment evaluation tests. The occurrence of the pressure ulcer was observed both immediately after operation in the operating room and 30 minutes postoperatively in the postanesthesia recovery room. The thirty-eight nursing interventions and activities were also recorded [12]. This study selected one perioperative outcome "patient is free from signs and symptoms of injury related to positioning" and related nursing interventions from the development of an outcome-oriented perioperative nursing data set in Taiwan." The content validation was ascertained via expert validity and the inclusion criteria were set at a CVI larger than 0.80 ; in addition, the CVI of above selected thirty-eight nursing intervention items was 1.0. In addition, in order to set up a consistent diagnosis of pretest and posttest pressure ulcers, the results of the test and retest reliability were examined by paired $t$-test ( $t=11.9, P<0.0001$ ); that is, the study nurses demonstrate accuracy of the data collection for pressure ulcers.

2.3. Statistical Analysis. The statistical analysis was performed using SAS 9.1 (SAS Institute, Cary, NC, USA). In the univariate analysis, the $\chi^{2}$-test and independent $t$-test method were adopted to assess the differences of the mean value of categorical and continuous variables, respectively. The logistic regression model was used to assess the effects of relevant factors on each type of pressure ulcer after adjustment for the covariates. Odds ratio (OR) and 95\% confidence interval (CI) were used for the independent effect of associated variables. A $P$ value of $<0.05$ was considered statistically significant. 
TABLE 1: The gender specific information of study patients $(n=297)$.

\begin{tabular}{|c|c|c|c|c|}
\hline Variables & $\begin{array}{c}\text { Female }(n=135) \\
\text { Number }(\%) \\
\text { or mean } \pm \text { SD }\end{array}$ & $\begin{array}{c}\text { Male }(n=162) \\
\text { Number }(\%) \\
\text { or mean } \pm \text { SD }\end{array}$ & $\begin{array}{c}\text { Total }(n=297) \\
\text { Number }(\%) \\
\text { or mean } \pm \text { SD }\end{array}$ & $\begin{array}{l}P \text { value for } \chi^{2} \text {-test } \\
\text { or } t \text {-test }\end{array}$ \\
\hline \multicolumn{5}{|l|}{ Categorical variables } \\
\hline \multicolumn{5}{|l|}{ Past disease } \\
\hline Yes & $94(69.6)$ & $122(75.3)$ & $216(72.7)$ & \multirow{2}{*}{0.27} \\
\hline No & $41(30.4)$ & $40(24.7)$ & $81(27.3)$ & \\
\hline \multicolumn{5}{|l|}{ Smoking } \\
\hline Yes & $9(6.7)$ & $46(28.4)$ & $55(18.6)$ & \multirow{2}{*}{$<0.0001$} \\
\hline No & $126(93.3)$ & $116(71.6)$ & $241(81.4)$ & \\
\hline \multicolumn{5}{|l|}{$\begin{array}{l}\text { Type of anesthesia (general } \\
\text { anesthesia) }\end{array}$} \\
\hline Yes & $99(73.3)$ & $99(61.1)$ & $198(66.7)$ & \multirow{2}{*}{0.03} \\
\hline No & $36(26.7)$ & $63(38.9)$ & $99(33.3)$ & \\
\hline \multicolumn{5}{|l|}{ Type of operation position } \\
\hline Supine & $88(65.2)$ & $94(58.0)$ & $182(61.3)$ & \multirow{5}{*}{0.17} \\
\hline Prone & $18(13.3)$ & 19 (11.7) & $37(12.5)$ & \\
\hline Lithotomy & $12(8.9)$ & $29(17.9)$ & $41(13.8)$ & \\
\hline Lateral & $13(9.6)$ & $18(11.1)$ & $31(10.4)$ & \\
\hline Others & $4(3.0)$ & $2(1.2)$ & $6(2.0)$ & \\
\hline \multicolumn{5}{|l|}{ Type of surgery } \\
\hline General surgery & $64(47.4)$ & $91(56.2)$ & $155(52.2)$ & \multirow{4}{*}{0.03} \\
\hline Neurosurgery & $13(9.6)$ & $11(6.8)$ & $24(8.1)$ & \\
\hline Orthopedics surgery & $52(38.5)$ & $42(25.9)$ & $94(31.7)$ & \\
\hline Cardiac surgery & $6(4.4)$ & $18(11.1)$ & $24(8.1)$ & \\
\hline \multicolumn{5}{|l|}{ Warmer used } \\
\hline Yes & $107(79.3)$ & $135(83.3)$ & $242(81.5)$ & \multirow{2}{*}{0.37} \\
\hline No & $28(20.7)$ & $27(16.7)$ & $55(18.5)$ & \\
\hline \multicolumn{5}{|l|}{ Shear } \\
\hline Yes & $67(49.6)$ & $80(49.4)$ & $147(49.5)$ & \multirow{2}{*}{0.97} \\
\hline No & $68(50.4)$ & $82(50.6)$ & $150(50.5)$ & \\
\hline \multicolumn{5}{|l|}{ Wet } \\
\hline Yes & $4(3.0)$ & $12(7.4)$ & $16(5.4)$ & \multirow{2}{*}{0.09} \\
\hline No & $131(97.0)$ & $150(92.6)$ & $281(94.6)$ & \\
\hline \multicolumn{5}{|l|}{ Heart-lung machine used } \\
\hline Yes & $4(3.0)$ & $6(3.7)$ & $10(3.4)$ & \multirow{2}{*}{0.72} \\
\hline No & $131(97.0)$ & $156(96.3)$ & $287(96.6)$ & \\
\hline \multicolumn{5}{|c|}{$\begin{array}{l}\text { Diastolic blood pressure less than } \\
60 \mathrm{mmHg} \text { during operation }\end{array}$} \\
\hline Yes & $104(77.0)$ & $111(68.5)$ & $215(72.4)$ & \multirow{2}{*}{0.10} \\
\hline No & $31(23.0)$ & $51(31.5)$ & $82(27.6)$ & \\
\hline \multicolumn{5}{|l|}{ Continuous variables } \\
\hline Operation age (yrs) & $59.9 \pm 14.5$ & $64.9 \pm 15.4$ & $62.6 \pm 15.2$ & 0.004 \\
\hline Body mass index $\left(\mathrm{Kg} / \mathrm{m}^{2}\right)$ & $24.8 \pm 4.4$ & $25.0 \pm 3.6$ & $24.9 \pm 4.0$ & 0.76 \\
\hline Hemoglobin (g/dL) & $13.2 \pm 6.8$ & $13.7 \pm 5.3$ & $13.4 \pm 6.0$ & 0.48 \\
\hline Hematocrit (\%) & $36.9 \pm 5.5$ & $38.6 \pm 6.5$ & $37.8 \pm 6.1$ & 0.02 \\
\hline Admission Braden score & $21.7 \pm 2.4$ & $21.6 \pm 2.3$ & $21.7 \pm 2.3$ & 0.72 \\
\hline
\end{tabular}


TABle 1: Continued.

\begin{tabular}{lcccc}
\hline Variables & $\begin{array}{c}\text { Female }(n=135) \\
\text { Number }(\%) \\
\text { or mean } \pm \text { SD }\end{array}$ & $\begin{array}{c}\text { Male }(n=162) \\
\text { Number }(\%) \\
\text { or mean } \pm \text { SD }\end{array}$ & $\begin{array}{c}\text { Total }(n=297) \\
\text { Number }(\%) \\
\text { or mean } \pm \text { SD }\end{array}$ & $\begin{array}{c}P \text { value for } \chi^{2} \text {-test } \\
\text { or } t \text {-test }\end{array}$ \\
\hline Time of operation (min) & $197.4 \pm 111.5$ & $210.8 \pm 145.6$ & $204.7 \pm 131.1$ & 0.38 \\
Number of nursing intervention & $35.9 \pm 8.2$ & $36.4 \pm 7.9$ & $36.2 \pm 8.0$ & 0.65 \\
$\begin{array}{l}\text { Ear temperature after operation }\left({ }^{\circ} \mathrm{C}\right) \\
\text { Total time of diastolic blood } \\
\text { pressure less than } 60 \mathrm{mmHg}(\mathrm{min})\end{array}$ & $35.9 \pm 0.8$ & $35.9 \pm 0.9$ & $35.9 \pm 0.9$ & 0.57 \\
\hline
\end{tabular}

\section{Results}

The gender specific information of the 297 study patients is shown in Table 1. The distribution of smokers (female: $6.7 \%$, male: $28.4 \%, P<0.0001$ ), type of anesthesia (female: $73.3 \%$, male: $61.1 \%, P=0.03$ ), type of general surgery (female: $47.4 \%$, male: $56.2 \%, P=0.03$ ), operation age (female: $59.9 \pm 14.5$, male: $64.9 \pm 15.4, P=0.004$ ), and hematocrit (female: $36.9 \pm$ 5.5, male: $38.6 \pm 6.5, P=0.02$ ) had statistical significant difference between male and female.

As Table 2 shows, there are 29 and 15 patients who were diagnosed as stage I immediate and thirty-minute-later pressure ulcer. The incidence of immediate and thirty-minutelater pressure ulcer is $9.8 \%(29 / 297)$ and $5.1 \%(15 / 297)$, respectively. Type of anesthesia (OR = 16.14, 95\% CI: 2.16-120.47), type of operation position (prone versus supine, $\mathrm{OR}=62.98$, 95\% CI: 16.98-233.55; lateral versus supine, OR $=14.32$, 95\% CI: 3.37-60.91), type of surgery (orthopedics surgery versus general surgery, $\mathrm{OR}=5.88,95 \% \mathrm{CI}: 2.24-15.43)$, operation age $(\mathrm{OR}=1.03,95 \% \mathrm{CI}: 1.00-1.06)$, admission Braden score $(\mathrm{OR}=$ 0.85, 95\% CI: 0.75-0.97), and number of nursing intervention $(\mathrm{OR}=0.95,95 \% \mathrm{CI}: 0.89-0.99)$ are significantly relevant to immediate pressure ulcers. In addition, the significant risk factors related to pressure ulcers of 30 minutes later included type of anesthesia (OR $=7.45,95 \% \mathrm{CI}$ : $1.00-57.51$ ), type of operation position (prone versus supine, $\mathrm{OR}=22.10$, 95\% CI: 5.72-85.43), type of surgery (orthopedics surgery versus general surgery, $\mathrm{OR}=18.33,95 \% \mathrm{CI}$ : 2.31-145.69; cardiac surgery versus general surgery, OR $=22.00,95 \% \mathrm{CI}$ : 2.19-221.34), heart-lung machine used ( $\mathrm{OR}=5.27,95 \% \mathrm{CI}$ : $1.02-27.34)$, operation age $(\mathrm{OR}=1.04,95 \% \mathrm{CI}: 1.00-1.09)$, admission Braden score ( $\mathrm{OR}=0.84,95 \% \mathrm{CI}$ : 0.71-0.98), and number of nursing intervention $(\mathrm{OR}=0.94,95 \% \mathrm{CI}$ : $0.90-0.98)$.

The effects of independent associated factors of each type of pressure ulcers are examined by the multiple logistic regression model in Table 3 . The statistically significantly associated risk factors related to immediate pressure ulcer include operation age ( $\mathrm{OR}=1.03,95 \% \mathrm{CI}: 1.00-1.08)$, type of anesthesia (general anesthesia) (yes versus no, $\mathrm{OR}=17.06$, 95\% CI: 2.09-49.43), type of operation position (nonsupine versus supine, $\mathrm{OR}=32.26,95 \% \mathrm{CI}: 4.48-48.79$ ), type of surgery (orthopedics surgery versus general surgery, OR = 3.33, 95\% CI: 1.05-10.61), admission Braden score (OR = 0.95, 95\% CI: 0.91-0.99), and number of nursing intervention $(\mathrm{OR}=0.94,95 \% \mathrm{CI}: 0.90-0.98)$. Operation age $(\mathrm{OR}=1.06$, 95\% CI: $1.00-1.12$ ), type of operation position (nonsupine versus supine, $\mathrm{OR}=18.18,95 \% \mathrm{CI}: 1.32-52.63)$, type of surgery (orthopedics surgery versus general surgery, OR = 9.29, 95\% CI: 1.05-28.50; cardiac surgery versus general surgery, OR $=22.60,95 \% \mathrm{CI}: 1.20-43.85)$, and number of nursing intervention ( $\mathrm{OR}=0.95,95 \% \mathrm{CI}: 0.91-0.99)$ are independently significant relevant to pressure ulcers of 30 minutes later after adjustment for confounding factors.

\section{Discussion}

4.1. Morbidity of Pressure Ulcer. Previous studies focused on nonblanchable erythema as the early identification of pressure ulcer and investigated the factors for developing into more severe pressure ulcers [13]. In this study, the reasons for evaluating pressure ulcer at two points of time were because blanchable erythema is the first clinical sign of pressure ulcer development, especially over a bony prominent area after surgery. Incidence of blanchable erythema and deterioration to pressure ulcer were reported on surgical patients [13]. Postoperative patients routinely stayed in the postanesthesia recovery room for at least two hours unmoved; blanchable erythema could worsen to pressure ulcer of either stage I or II. Detecting the blanchable erythema is expected to provide appropriate care to prevent pressure ulcer.

Early detection of pressure ulcer has been emphasized because it could prevent skin alteration from progressing to skin loss. Patients are exposed to complications during surgical operations for reasons associated with the surgical position and for many other causes. It is known that pressure ulcers are lesions caused by unrelieved pressure that results in damage to the underlying tissue. This disorder is a health problem that brings both high material and emotional losses to patients [5]. Generally, these are the results of soft tissue compression between a bony prominence and an external surface for a prolonged period of time [14]. Knowledge of pressure ulcer epidemiology is therefore crucial in managing this disorder, not only for planning preventive programs, but also for the identification of the best therapeutic strategy. The incidence of pressure ulcer amongst different test populations appears to vary, differing among different studies conducted in different countries. In this study, the incidence of immediate and thirty-minute-later pressure ulcers is $9.8 \%$ and $5.1 \%$, respectively. Incidence rates of pressure ulcers as low as $0.4 \%$ to as high as $38 \%$ have been reported in the inpatient department while prevalence has been reported as $3.5 \%$ to $69 \%[2,8,9,15-17]$. In long-term care facilities, 
TABLE 2: Univariate analysis for comparison of characteristics in pressure ulcers among study population $(n=297)$.

\begin{tabular}{|c|c|c|c|c|c|c|}
\hline & \multicolumn{6}{|c|}{ Types of pressure ulcers } \\
\hline & \multicolumn{3}{|c|}{ Immediately } & \multicolumn{3}{|c|}{30 minutes later } \\
\hline & $\begin{array}{c}\text { Yes } \\
(n=29)\end{array}$ & $\begin{array}{c}\text { No } \\
(n=268)\end{array}$ & OR $(95 \% \mathrm{CI})$ & $\begin{array}{c}\text { Yes } \\
(n=15)\end{array}$ & $\begin{array}{c}\text { No } \\
(n=282) \\
\end{array}$ & OR (95\% CI) \\
\hline \multicolumn{7}{|l|}{ Categorical variables } \\
\hline \multicolumn{7}{|l|}{ Gender } \\
\hline Female & 13 & 122 & 0.97 & 5 & 130 & 0.59 \\
\hline Male & 16 & 146 & $(0.45-2.10)$ & 10 & 152 & $(0.20-1.75)$ \\
\hline \multicolumn{7}{|l|}{ Past disease } \\
\hline Yes & 21 & 195 & 0.98 & 11 & 205 & 1.03 \\
\hline No & 8 & 73 & $(0.42-2.32)$ & 4 & 77 & $(0.32-3.34)$ \\
\hline \multicolumn{7}{|l|}{ Smoking } \\
\hline Yes & 4 & 51 & 0.68 & 3 & 52 & 1.11 \\
\hline No & 25 & 217 & $(0.23-2.04)$ & 12 & 230 & $(0.30-4.06)$ \\
\hline \multicolumn{7}{|c|}{$\begin{array}{l}\text { Type of anesthesia (general } \\
\text { anesthesia) }\end{array}$} \\
\hline Yes & 28 & 170 & 16.14 & 14 & 184 & 7.45 \\
\hline No & 1 & 98 & $(2.16-120.47)$ & 1 & 98 & $(1.00-57.51)$ \\
\hline \multicolumn{7}{|l|}{ Type of operation position } \\
\hline Supine & 3 & 179 & 1.00 & 3 & 179 & 1.00 \\
\hline Prone & 19 & 18 & $62.98(16.98-233.55)$ & 10 & 27 & $22.10(5.72-85.43)$ \\
\hline Lithotomy & 1 & 40 & $1.49(0.15-14.72)$ & 0 & 41 & - \\
\hline Lateral & 6 & 25 & $14.32(3.37-60.91)$ & 2 & 29 & $4.11(0.66-25.70)$ \\
\hline Others & 0 & 6 & - & 0 & 6 & - \\
\hline \multicolumn{7}{|l|}{ Type of surgery } \\
\hline General surgery & 6 & 149 & 1.00 & 1 & 154 & 1.00 \\
\hline Neurosurgery & 2 & 22 & $2.25(0.43-11.89)$ & 1 & 23 & $6.70(0.40-110.79)$ \\
\hline Orthopedics surgery & 18 & 76 & $5.88(2.24-15.43)$ & 10 & 84 & $18.33(2.31-145.69)$ \\
\hline Cardiac surgery & 3 & 21 & $3.55(0.82-15.26)$ & 3 & 21 & $22.00(2.19-221.34)$ \\
\hline \multicolumn{7}{|l|}{ Warmer used } \\
\hline Yes & 28 & 214 & 7.06 & 15 & 227 & - \\
\hline No & 1 & 54 & $(0.94-53.04)$ & 0 & 55 & \\
\hline \multicolumn{7}{|l|}{ Shear } \\
\hline Yes & 12 & 135 & 0.70 & 6 & 141 & 0.67 \\
\hline No & 17 & 133 & $(0.32-1.51)$ & 9 & 141 & $(0.23-1.92)$ \\
\hline \multicolumn{7}{|l|}{ Wet } \\
\hline Yes & 1 & 15 & 0.60 & 0 & 16 & - \\
\hline No & 28 & 253 & $(0.08-4.73)$ & 15 & 266 & \\
\hline \multicolumn{7}{|l|}{ Heart-lung machine used } \\
\hline Yes & 2 & 8 & 2.41 & 2 & 8 & 5.27 \\
\hline No & 27 & 260 & $(0.49-11.92)$ & 13 & 274 & $(1.02-27.34)$ \\
\hline \multicolumn{7}{|c|}{$\begin{array}{l}\text { Diastolic blood pressure } \\
\text { less than } 60 \mathrm{mmHg} \text { during } \\
\text { operation }\end{array}$} \\
\hline Yes & 24 & 191 & 1.94 & 12 & 203 & 1.56 \\
\hline No & 5 & 77 & $(0.71-5.26)$ & 3 & 79 & $(0.43-5.66)$ \\
\hline
\end{tabular}


TABLE 2: Continued.

\begin{tabular}{|c|c|c|c|c|}
\hline & \multicolumn{4}{|c|}{ Types of pressure ulcers } \\
\hline & \multicolumn{2}{|r|}{ Immediately } & \multicolumn{2}{|r|}{30 minutes later } \\
\hline & $\begin{array}{c}\text { Yes } \\
(n=29)\end{array}$ & $\begin{array}{c}\text { No } \\
(n=268)\end{array}$ & $\begin{array}{c}\text { Yes } \\
(n=15)\end{array}$ & $\begin{array}{c}\text { No } \\
(n=282)\end{array}$ \\
\hline \multicolumn{5}{|l|}{ Continuous variables } \\
\hline Age (yrs) & - & $1.03(1.00-1.06)$ & - & $1.04(1.00-1.09)$ \\
\hline Body mass index $\left(\mathrm{Kg} / \mathrm{m}^{2}\right)$ & - & $1.03(0.93-1.13)$ & - & $1.00(0.87-1.14)$ \\
\hline Hemoglobin (g/dL) & - & $0.99(0.92-1.07)$ & - & $0.99(0.89-1.10)$ \\
\hline Hematocrit (\%) & - & $0.99(0.93-1.05)$ & - & $1.04(0.95-1.14)$ \\
\hline Admission Braden score & - & $0.85(0.75-0.97)$ & - & $0.84(0.71-0.98)$ \\
\hline Time of operation (min) & - & $1.00(0.98-1.02)$ & - & $1.00(0.99-1.01)$ \\
\hline $\begin{array}{l}\text { Number of nursing } \\
\text { intervention }\end{array}$ & - & $0.95(0.89-0.99)$ & - & $0.94(0.90-0.98)$ \\
\hline $\begin{array}{l}\text { Ear temperature after } \\
\text { operation }\end{array}$ & - & $0.93(0.60-1.44)$ & - & $0.77(0.43-1.38)$ \\
\hline $\begin{array}{l}\text { Total time of diastolic } \\
\text { blood pressure less than } \\
60 \mathrm{mmHg}(\mathrm{min})\end{array}$ & - & $1.00(0.99-1.01)$ & - & $1.00(0.99-1.02)$ \\
\hline
\end{tabular}

TABLE 3: Multivariate analysis using logistic regression model of risk factors associated with the pressure ulcers among study population $(n=297)$.

\begin{tabular}{|c|c|c|c|c|}
\hline \multirow{3}{*}{ Variable } & \multicolumn{4}{|c|}{ Types of pressure ulcers (yes versus no) } \\
\hline & \multicolumn{2}{|c|}{ Immediately } & \multicolumn{2}{|c|}{30 minutes later } \\
\hline & OR & $(95 \% \mathrm{CI})$ & OR & $(95 \% \mathrm{CI})$ \\
\hline Gender (female versus male) & 0.98 & $0.39-2.61$ & 0.65 & $0.18-2.27$ \\
\hline Operation age (yrs) & 1.03 & $1.00-1.08$ & 1.06 & $1.00-1.12$ \\
\hline Type of anesthesia (general anesthesia) (yes versus no) & 17.06 & $2.09-49.43$ & 5.29 & $0.56-46.71$ \\
\hline Type of operation position (nonsupine versus supine) & 32.26 & $4.48-48.79$ & 18.18 & $1.32-52.63$ \\
\hline \multicolumn{5}{|l|}{ Type of surgery } \\
\hline General surgery & 1.00 & - & 1.00 & - \\
\hline Neurosurgery & 1.29 & $0.20-8.58$ & 5.57 & $0.28-19.69$ \\
\hline Orthopedics surgery & 3.33 & $1.05-10.61$ & 9.29 & $1.05-28.50$ \\
\hline Cardiac surgery & 6.98 & $0.72-39.88$ & 22.60 & $1.20-43.85$ \\
\hline Heart-lung machine used (yes versus no) & 5.24 & $0.51-43.55$ & 7.58 & $0.51-49.28$ \\
\hline Admission Braden score & 0.95 & $0.91-0.99$ & 0.93 & $0.80-1.09$ \\
\hline Number of nursing intervention & 0.94 & $0.90-0.98$ & 0.95 & $0.91-0.99$ \\
\hline The Hosmer-Lemeshow test & \multicolumn{2}{|c|}{$\chi_{(8)}^{2}=3.79, P=0.88$} & \multicolumn{2}{|c|}{$\chi_{(8)}^{2}=4.17, P=0.84$} \\
\hline c-statistics & \multicolumn{2}{|c|}{0.914} & \multicolumn{2}{|c|}{0.917} \\
\hline
\end{tabular}

the reported incidence is between $2.2 \%$ and $23.9 \%$, while in home care setting the incidence varies from 0 to $17 \%$ [15]. Many trials have chosen not to include them since they are difficult to be reliably detected although stage 1 ulcers are frequently encountered [18]. Further well-designed epidemiological investigations of pressure ulcers in various settings are still required. In addition, not surprisingly, the hospital stay is longer in pressure ulcer patients with both excess likelihood of nosocomial, renal infections and the hospital readmission rate. A previous study based on the hospital billing codes also revealed an increase in the number of hospital stays involving pressure ulcers by nearly $80 \%$ [19]. This implies that pressure ulcers result in an exponential increase in the healthcare burden and financial requirement for these patients.

4.2. Implications as Regards Associated Risk Factors for Pressure Ulcer. In Taiwan, one study on elective surgical patient revealed that the incidence of the perioperative pressure ulcer in surgical patients was $7.0 \%$, and the significant factors associated with pressure ulcer development were age, preoperative chronic cerebral arterial disease, preoperative BMI, total protein level, albumin level, Braden scale scores, operative time, body temperature, and intraoperative blood pressure [12]. Previous study also indicated that preoperatively all patients carry a risk for pressure ulcers, that risk 
TABLE 4: The study flowchart of the recruitment.

\begin{tabular}{|c|c|c|c|}
\hline \multicolumn{2}{|c|}{ Preoperative $N=297$} & \multirow{2}{*}{$\begin{array}{l}\text { Intraoperative } N=297 \\
\text { Operation day during } \\
\text { procedure }\end{array}$} & \multirow{2}{*}{$\begin{array}{l}\text { Postoperative } N=297 \\
\text { Operation day in } \\
\text { postanesthesia recovery } \\
\text { room }\end{array}$} \\
\hline The day before operation & $\begin{array}{l}\text { Operation day when } \\
\text { arrived in holding area }\end{array}$ & & \\
\hline $\begin{array}{l}\text { Selected patients from } \\
\text { next day's elective } \\
\text { surgical schedule } \\
\text { included patients who } \\
\text { (1) agreed to participate, } \\
\text { (2) have a first time } \\
\text { elective surgery, } \\
\text { (3) have procedure } \\
\text { lasting more than } 30 \\
\text { minutes, } \\
\text { (4) are under spinal or } \\
\text { general anesthesia, and } \\
\text { (5) have no existing } \\
\text { pressure ulcers nor any } \\
\text { traumas before surgery }\end{array}$ & $\begin{array}{l}\text { Assessment of } \\
\text { (1) the Braden scale, and } \\
\text { (2) patient demographic } \\
\text { characteristics and health } \\
\text { status }\end{array}$ & $\begin{array}{l}\text { Assessment of } \\
\text { (1) pressure ulcers record } \\
\text { sheet, } \\
\text { (2) related nursing } \\
\text { interventions and activities, } \\
\text { and } \\
\text { (3) operation related data: } \\
\text { operation time, type of } \\
\text { anesthesia, positioning, } \\
\text { body temperature, and so } \\
\text { forth }\end{array}$ & $\begin{array}{l}\text { Assessment of } \\
\text { (1) pressure ulcers record } \\
\text { sheet and } \\
\text { (2) related evaluation to the } \\
\text { nursing interventions and } \\
\text { activities }\end{array}$ \\
\hline
\end{tabular}

postoperatively and that it is necessary to use a measure of risk to identify patients' risk for surgery-related pressure ulcer $[5,20]$. In this study, none of the preoperative physical condition (i.e., past disease, hemoglobin, hematocrit, and smoking habit), nutrition (i.e., BMI and albumin), and intraoperative status (time of the operation, total time of diastolic blood pressure less than $60 \mathrm{mmHg}$, application of heart-lung machine, body temperature after procedure, and shear power and wetness) variables measured emerged as statistically significant risk factors for pressure ulcer development. It is possible that the control of the patient physical condition, such as blood pressure and body temperature, was satisfactory and did not affect the development of the pressure ulcer. And this also may be related to adequate preventive nursing interventions performed perioperatively.

The estimated incidence of pressure ulcers increased with operation age in this study. Such a finding is consistent with results of other studies conducted elsewhere [21]. It means that the long-term exposure to many other risk factors among elder persons may also account for the increased probability of developing pressure ulcers. In addition, the reduced risks for pressure ulcers found in relation to admission Braden score increased. The Braden Pressure Ulcer Risk Assessment scale was developed by Barbara Braden in 1987 and there have been many studies in the US and UK which have shown its validity and reliability $[1,5,21]$. In the determination of risk preoperatively and postoperatively with the Braden Pressure Ulcer Risk Assessment scale that was used in this study and in the determination of areas at risk [5], it could offer detailed clues for planning appropriate patient interventions for pressure ulcers.

Our results also support the hypothesis that the number of nursing interventions is at lower risk for development of pressure ulcers. The result of the study will improve perioperative nursing and provide the nursing administrators with the effects of the clinical perioperative nursing for the pressure ulcers prevention. A multidisciplinary approach is essential in prevention of pressure ulcers and a large part of the responsibility falls on nurses in this approach. Nursing staff are responsible in the institute they work in for identifying patients at risk for pressure ulcers and carrying out the preventive measures [5]. "Prevention is better than cure" is best emphasized in the case of pressure ulcers. This condition is absolutely preventable with care, compassion, and dedication towards the care of patients. Prevention is directed towards taking care of the extrinsic and intrinsic factors [2].

The variables including position, general anesthesia, and type of surgery had a statistically significant association with incident pressure ulcers in this study. Evidence was found that the chance of a patient who used general anesthesia to present pressure ulcers is 4.8 times greater than that who used local anesthesia $(P=0.024)$. It is certain that this correlation is also associated with surgery duration and size, as longer surgeries usually make use of general anesthesia [22]. It points at general anesthesia as a factor predisposing the occurrence of pressure ulcers due to immobilization and absence of skin sensitivity, in addition to changes in blood pressure, tissue perfusion, the patient's response to pain, and the oxygen and carbon dioxide exchange $[3,22]$. In addition, it should be noted that neurosurgeries in the ventral position include spinal surgeries, and this could have determined the higher pressure ulcers incidence observed [22]. This hypothesis is also supported by a study that found a higher pressure ulcers incidence in patients submitted to spinal surgeries [23].

4.3. Methodological Considerations. Although using a followup study design could clarify the temporal relationship of potential risk factors for the development of pressure ulcer, there are some drawbacks in this study. A major limitation was the potential self-selection bias due to the hospital-based study design; it is not entirely representative of the whole general population. Secondly, a logistic regression of a binary response variable $(Y)$ on a binary independent variable $(X)$ 
with a sample size of 297 observations (of which $60 \%$ are in the group $X=0$ and $40 \%$ are in the group $X=1$ ) achieves $74 \%$ power at a 0.05 significance level to detect a change in $\operatorname{Prob}(Y=1)$ from the baseline value of 0.097 to 0.212 . This change corresponds to an odds ratio of 2.500. An adjustment was made since a multiple regression of the independent variable of interest on the other independent variables in the logistic regression obtained an $R$-squared of 0.100 in this study [24]. Although the identifications of pressure ulcers based on clinician-researchers directly examined patients meant estimates are accurate, the sample sizes tend to be relatively small and involve only a single facility, making generalizability uncertain, such that the type of anesthesia had broad confidence interval possibly due to the small number of local anesthesia. Thirdly, we only observed immediate and thirty-minute-later pressure ulcers. There is a possibility that they may have been affected by postoperative risk factors because some of the pressure ulcers were seen after the third postoperative day [5]. The true incidence of pressure ulcers would be underestimated. Further long-term studies should be conducted with a larger sample size to explore the morbidity and consequences of pressure ulcers and plausible biological mechanisms underlying its development.

\section{Conclusion}

In conclusion, admission Braden score and number of nursing intervention are well-established protected factor for the development of pressure ulcers. Our study shows that older operation age, type of anesthesia, type of operation position, and type of surgery are also associated with the development of pressure ulcers.

\section{Conflict of Interests}

We certify that, within the past 5 years and foreseeable future, all our affiliations with or financial involvement in any organization or entity with a financial interest in or financial conflict with the subject matter or materials discussed in the paper (e.g., employment, consultancies, honoraria, stock ownership or options, expert testimony, grants or patents received or pending, and royalties) are completely disclosed.

\section{Acknowledgment}

This study was supported by the Grants from the Taipei Veterans General Hospital, Taipei, Taiwan (V95A-140).

\section{References}

[1] O. Uzun and M. Tan, "A prospective, descriptive pressure ulcer risk factor and prevalence study at a university hospital in Turkey," Ostomy Wound Management, vol. 53, no. 2, pp. 44-56, 2007.

[2] K. Agrawal and N. Chauhan, "Pressure ulcers: back to the basics," Indian Journal of Plastic Surgery, vol. 45, no. 2, pp. 244254, 2012.

[3] A. Schultz, "Predicting and preventing pressure ulcers in surgical patients," AORN Journal, vol. 81, no. 5, pp. 985-1006, 2005.
[4] R. M. Allman, "Pressure ulcer prevalence, incidence, risk factors, and impact," Clinics in Geriatric Medicine, vol. 13, no. 3, pp. 421-436, 1997.

[5] M. Karadag and N. Gümüskaya, "The incidence of pressure ulcers in surgical patients: a sample hospital in Turkey," Journal of Clinical Nursing, vol. 15, no. 4, pp. 413-421, 2006.

[6] L. Gunningberg, "Risk, prevalence and prevention of pressure ulcers in three Swedish healthcare settings," Journal of Wound Care, vol. 13, no. 7, pp. 286-290, 2004.

[7] S. R. Burdette-Taylor and J. Kass, "Heel ulcers in critical care units: a major pressure problem," Critical Care Nursing Quarterly, vol. 25, no. 2, pp. 41-53, 2002.

[8] E. S. M. Shahin, T. Dassen, and R. J. G. Halfens, "Incidence, prevention and treatment of pressure ulcers in intensive care patients: a longitudinal study," International Journal of Nursing Studies, vol. 46, no. 4, pp. 413-421, 2009.

[9] B. Leblebici, N. Turhan, M. Adam, and M. N. Akman, "Clinical and epidemiologic evaluation of pressure ulcers in patients at a university hospital in Turkey," Journal of Wound, Ostomy and Continence Nursing, vol. 34, no. 4, pp. 407-411, 2007.

[10] J. Cox, "Predictive power of the braden scale for pressure sore risk in adult critical care patients: a comprehensive review," Journal of Wound, Ostomy and Continence Nursing, vol. 39, no. 6, pp. 613-621, 2012.

[11] National Pressure Ulcer Advisory Pane, Pressure Ulcers: Incidence, Economics, Risk Assessment, Consensus Development Conference Statement, S-N Publications, West Dundee, Ill, USA, 1989, http://www.npuap.org/pr2/htm.

[12] F. L. Shaw, H. Pan, Y. J. Lu et al., "Development of an outcomeoriented perioperative nursing data set in Taiwan," Veterans General Hospital Nursing, vol. 22, no. 4, pp. 329-338, 2005.

[13] C. Konishi, J. Sugama, H. Sanada et al., "A prospective study of blanchable erythema among university hospital patients," International Wound Journal, vol. 5, no. 3, pp. 470-475, 2008.

[14] D. R. Thomas, "The new F-tag 314: prevention and management of pressure ulcers," Journal of the American Medical Directors Association, vol. 7, no. 8, pp. 523-531, 2006.

[15] J. Cuddigan, E. A. Ayello, C. Sussman, and S. Baranoski, "Pressure ulcers in America: prevalence, incidence, and implications for the future. An executive summary of the National Pressure Ulcer Advisory Panel monograph," Advances in Skin \& Wound Care, vol. 14, no. 4, pp. 208-215, 2001.

[16] M. Meehan, "Multisite pressure ulcer prevalence survey," Decubitus, vol. 3, no. 4, pp. 14-17, 1990.

[17] D. G. Inan and G. Oztunç, "Pressure ulcer prevalence in Turkey: a sample from a university hospital," Journal of Wound, Ostomy and Continence Nursing, vol. 39, no. 4, pp. 409-413, 2012.

[18] "Pressure ulcers prevalence, cost and risk assessment: consensus development conference statement-the National Pressure Ulcer Advisory Panel," Decubitus, vol. 2, no. 2, pp. 24-28, 1989.

[19] C. A. Russo, C. Steiner, and W. Spector, Hospitalizations Related to Pressure Ulcers among Adults 18 Years and Older, 2006, HCUP Statistical Brief \#64, Agency for Healthcare Research and Quality, Rockville, Md, USA, 2008, http://www.hcup-us.ahrq.gov/reports/statbriefs/sb64.pdf.

[20] D. Armstrong and P. Bortz, "An integrative review of pressure relief in surgical patients," AORN Journal, vol. 73, no. 3, pp. 645650, 2001.

[21] M. F. Cremasco, F. Wenzel, S. S. Zanei, and I. Y. Whitaker, "Pressure ulcers in the intensive care unit: the relationship between nursing workload, illness severity and pressure ulcer 
risk," Journal of Clinical Nursing, vol. 22, no. 15-16, pp. 2183-2191, 2013.

[22] K. C. Scarlatti, J. L. Michel, M. A. Gamba, and M. G. de Gutiérrez, "Pressure ulcers in surgery patients: incidence and associated factors," Revista da Escola de Enfermagem da USP, vol. 45, no. 6, pp. 1372-1379, 2011.

[23] H. Sanada, T. Nagakawa, M. Yamamoto, K. Higashidani, H. Tsuru, and J. Sugama, "The role of skin blood flow in pressure ulcer development during surgery," Advances in Wound Care, vol. 10, no. 6, pp. 29-34, 1997.

[24] F. Y. Hsieh, D. A. Block, and M. D. Larsen, "A simple method of sample size calculation for linear and logistic regression," Statistics in Medicine, vol. 17, no. 14, pp. 1623-1634, 1998. 


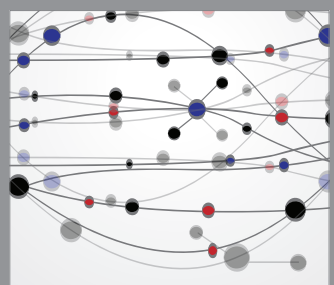

The Scientific World Journal
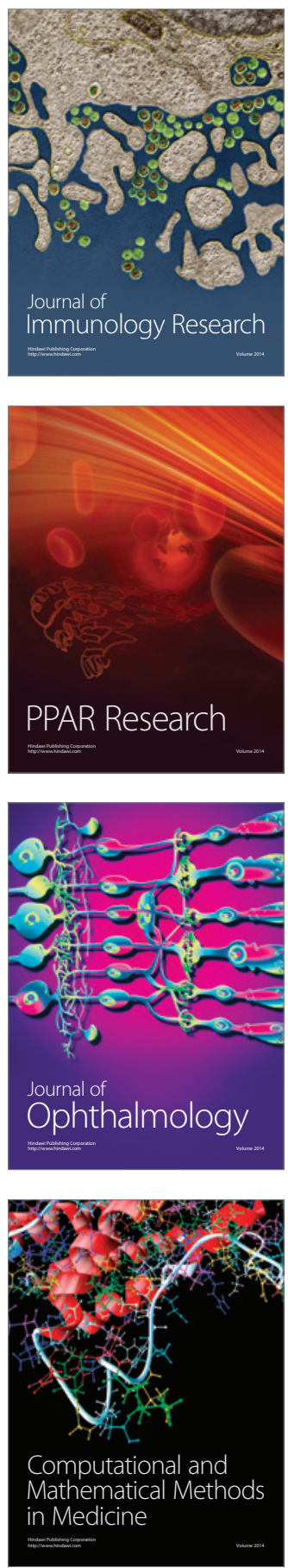

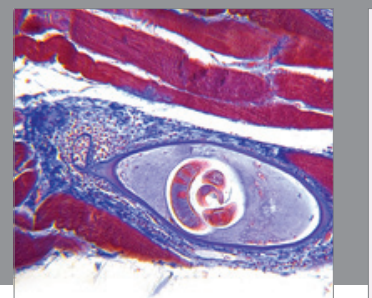

Gastroenterology

Research and Practice
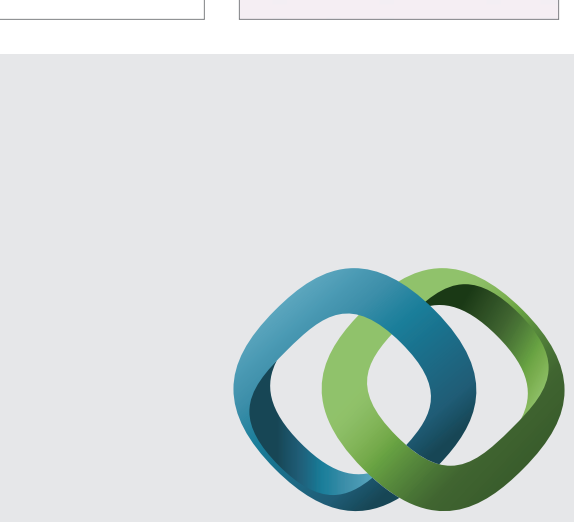

\section{Hindawi}

Submit your manuscripts at

http://www.hindawi.com
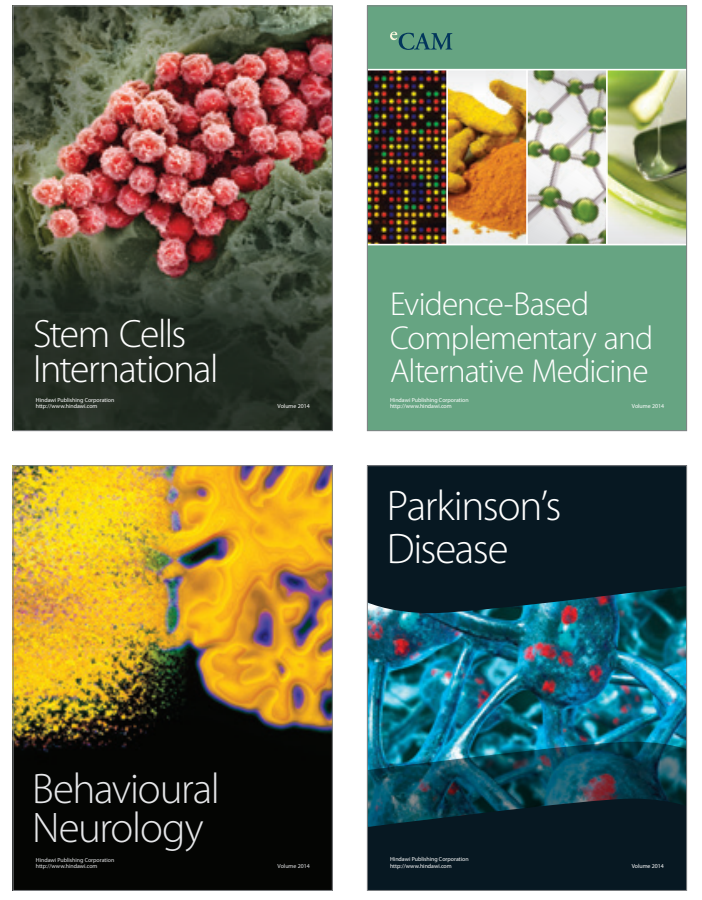
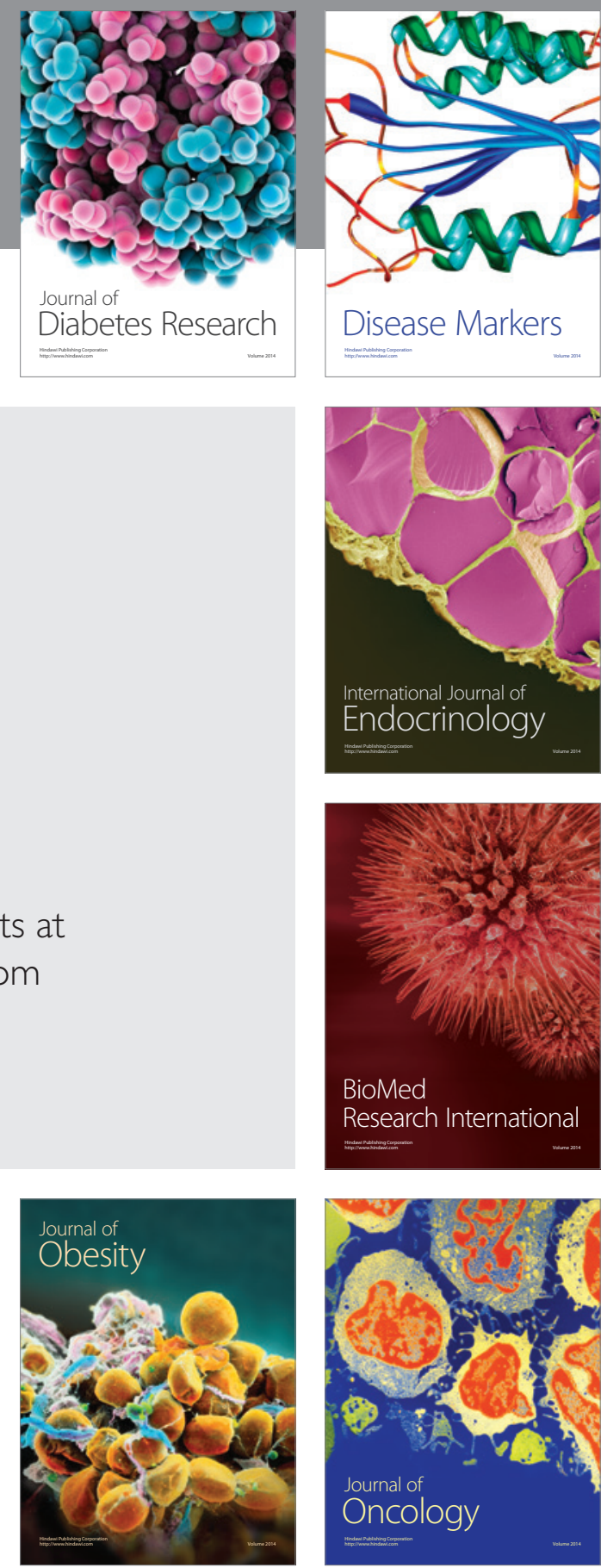

Disease Markers
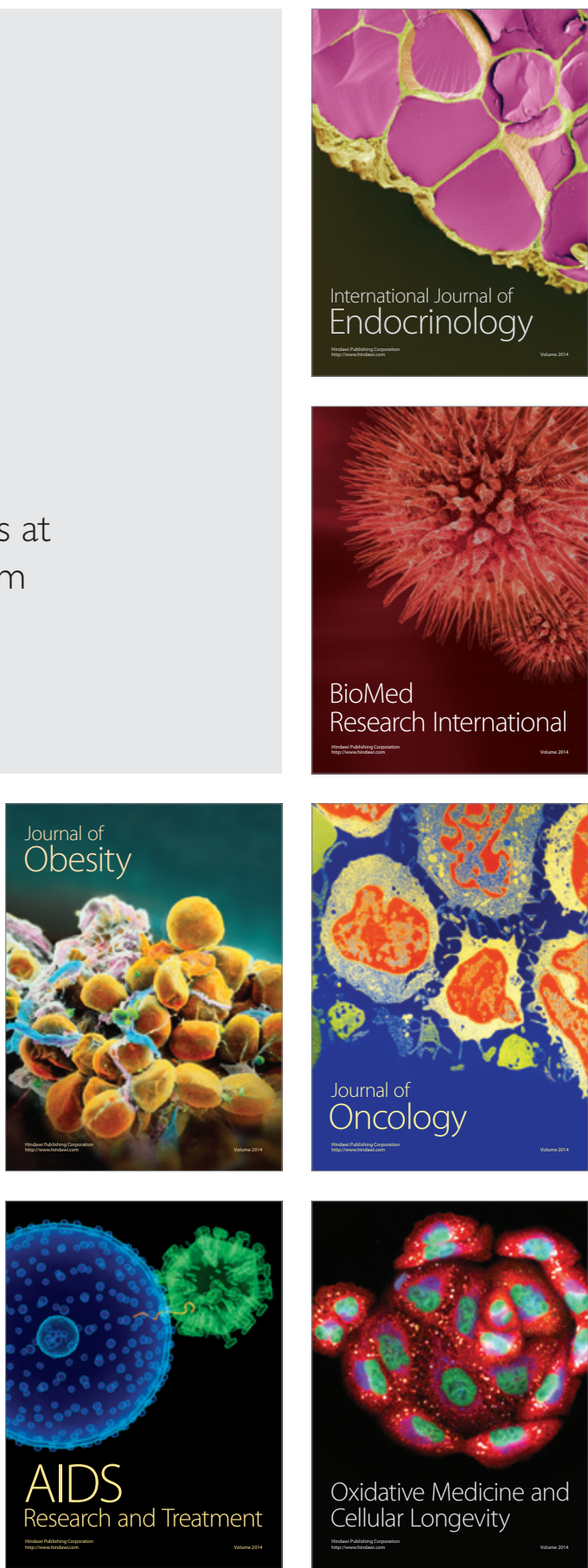